\title{
Airway resistance measured by the interrupter technique: normative data for 2-10 year olds of three ethnicities
}

\author{
S A McKenzie, E Chan, I Dundas, P D Bridge, C S Pao, M Mylonopoulou, M J R Healy
}

Arch Dis Child 2002;87:248-251

See end of article for authors' affiliations

Correspondence to: Dr S A McKenzie, 2nd

floor, Fielden House, Royal London Hospital,

Whitechapel, London

El 1BB, UK:

s.a.mckenzie@qmul.ac.uk

Accepted 10 April 2002
Background and Aims: The measurement of airway resistance using the interrupter technique $\left(R_{\text {int }}\right)$ is feasible in preschool children and other subjects unable to undertake spirometry. This makes it potentially useful for the measurement of lung function in these groups. Commercial devices use different algorithms to measure pressure and flow from which $R_{\text {int }}$ is derived. This study provides normative values for British children using devices from a single manufacturer.

Methods: $\mathrm{R}_{\text {int }}$ was measured in 236 healthy children of three ethnic groups (Afro-Caribbean and black African, Bangladeshi, and white British) aged 2-10 years using Micro Medical devices. Software in the devices calculated $R_{\text {int }}$ from pressure measured by the two point, back extrapolation method from the pressure transient during valve closure, with flow measured just before valve closure.

Results: $R_{\text {int }}$ is related to both age and height, but when age is allowed for there is not a significant relation with height. Neither gender nor any of the ethnicities studied was significantly related to $R_{\text {int }}$.

Discussion: These measurements in healthy children using this technique may be used as reference data for similar populations.
$\mathrm{T}$ he measurement of airway resistance by the interrupter method $\left(\mathrm{R}_{\mathrm{int}}\right)$ has been developed by a number of groups for clinical use and as a research tool. The method is particularly suitable for subjects who cannot undertake standard lung function tests, such as preschool children and schoolchildren who are unable to undertake spirometry. ${ }^{1-7}$ The ability to monitor the progress of lung disease and to measure the effect of therapeutic interventions in these groups is quite limited. Much is already known about the technical aspects of the measurement of $\mathrm{R}_{\mathrm{int}}$ and its repeatability in young children. ${ }^{8}$

Commercial equipment for measuring $\mathrm{R}_{\mathrm{int}}$ is now available. Undertaking the test is not complicated, even in a busy environment, ${ }^{6}$ and so it is possible to measure $\mathrm{R}_{\mathrm{int}}$ outside specialist centres. It is therefore important to provide reference values for normal children using these devices. In Europe, manufacturers of interrupter equipment include Micro Medical (Micro Medical Ltd, Gillingham, UK) and Jaeger (E Jaeger, Wurzburg, Germany). Reference data for healthy children aged 6-11 years, used in the Micro Medical equipment, have been obtained from a group of Korean children. ${ }^{9}$ There are also data for Dutch children which include only a small number under 4 years, ${ }^{10}$ and for Italian preschool children. ${ }^{11}$ Reference data using the Jaeger equipment have been published from Danish children aged 2-7 years, ${ }^{12}$ and a Dutch population with the youngest subjects age 9 years. ${ }^{13}$ The two devices use quite different algorithms for the calculation of pressure and flow from which, in turn, $\mathrm{R}_{\text {int }}$ is calculated and so reference data for each are needed. Data from a small group of French children made with a non-commercial device have also been published.

The purpose of this paper is to report measurements of $R_{\text {int }}$, using Micro Medical interrupter devices, in healthy east London children aged 2-10 years. This population is of particular interest as within it there are three large indigenous ethnic groups whose measurements can be compared. Our data will be compared to other published data.

\section{SUBJECTS AND METHODS}

\section{Subjects}

Subjects were children living in the east London districts of Tower Hamlets and City and Hackney. They were considered to have no respiratory problems if they met acceptable stand$\operatorname{ards}^{14}$ : absence of acute disease or reported respiratory symptoms (such as cough or difficulty in breathing); chronic respiratory disease or symptoms; disorders, such as neurological disease, likely to affect the respiratory system; and no history of upper respiratory tract infection in the three weeks before the test. Ethnicity was classified as Afro-Caribbean (this group included black Africans), Bangladeshi, and white British. In the 1999 local census, these groups were represented in the study population as follows: Afro-Caribbean 10\%, Bangladeshi $45 \%$, white British $37 \%$. Children of mixed ethnic parentage or from other ethnicities were excluded. Measurements of $\mathrm{R}_{\mathrm{int}}$ were undertaken either on hospital premises or in schools. Those studied in hospital were patients who were attending for the ambulatory treatment of unrelated conditions such as fractures, or patients' healthy siblings.

\section{Methods}

$\mathrm{R}_{\text {int }}$ was measured using two commercial devices (Microlab 4000 and MicroRint, Micro Medical Ltd, Gillingham, UK). In both devices flow is measured immediately before valve closure. Pressure is measured in both using a two point linear back extrapolation method. The time at valve closure $\left(\mathrm{T}_{0}\right)$ is arbitrarily defined as the time at which $25 \%$ of the difference between the baseline pressure and the first clearly defined pressure peak preceding oscillation is reached. ${ }^{15}$ In both devices change in pressure is measured at the mouth following valve closure $(\mathrm{Pmo}(\mathrm{t}))$ by back extrapolating through $10 \mathrm{~ms}$ portions centred on $\mathrm{T}_{0}+30 \mathrm{~ms}$ and $\mathrm{T}_{0}+70 \mathrm{~ms}$. The MicroRint extrapolates pressure to $\mathrm{T}_{0}$ and the Microlab 4000 to $\mathrm{T}_{0}+15 \mathrm{~ms}$. Although the extrapolation to $\mathrm{T}_{0}+15 \mathrm{~ms}$ would be expected to result in a higher pressure measurement and thus higher $\mathrm{R}_{\text {int }}$ measurements, it has been shown that measurements in children using the two devices show no systematic bias. ${ }^{16}$ This probably reflects a coefficient of variation of each measurement of about $15 \%,{ }^{17}$ which is likely to obscure small differences in $\mathrm{R}_{\mathrm{int}}$. As part of our own laboratory's quality control procedures, measurements have been made with both devices in 60 children aged $2-10$ years with a wide range of $\mathrm{R}_{\text {int }}$. The mean ratio of measurements made with the two devices, Microlab 4000/MicroRint, is 0.99 (95\% confidence 


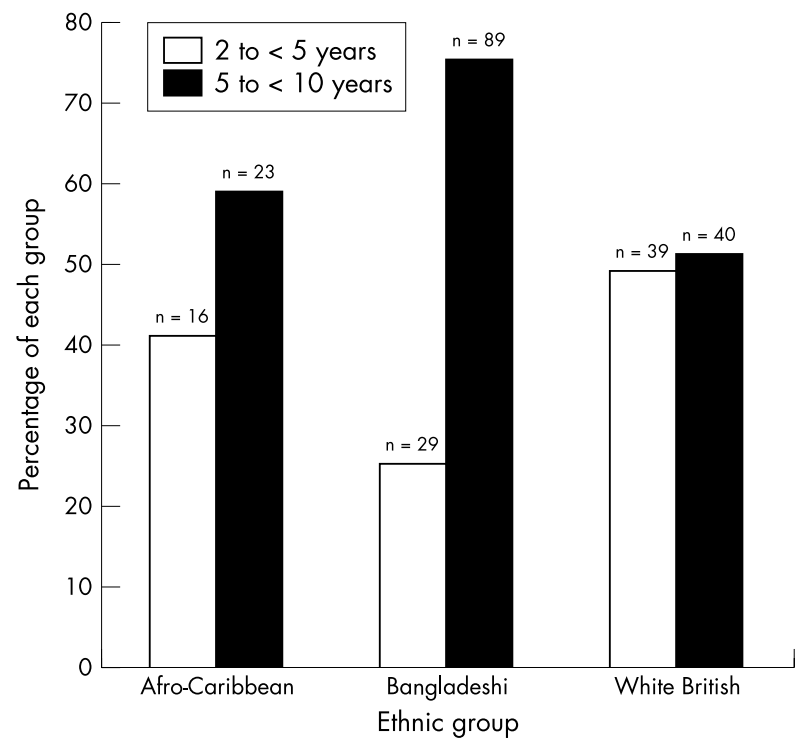

Figure 1 Ethnicity and age.

\begin{tabular}{|llll|}
\hline \multicolumn{3}{|c|}{ Table 1} & \multicolumn{3}{l}{ Heights as $\mathrm{z}$ scores for age } \\
\hline & Afro-Caribbeans & Bangladeshis & White British \\
\cline { 2 - 4 } & $(\mathrm{n}=39)$ & $(\mathrm{n}=118)$ & $(\mathrm{n}=79)$ \\
\hline Mean z score & +0.42 & -0.27 & -0.06 \\
SD & 1.03 & 1.19 & 1.07 \\
\hline
\end{tabular}

Table 2 Multiple regression of $\log _{10} R_{\text {int }}$ on age, height, gender, and ethnicity

\begin{tabular}{lcll}
\hline & Coefficients & Standard error & $p$ value \\
\hline Age $(y)$ & -0.0310 & 0.00819 & 0.0002 \\
Height $(\mathrm{cm})$ & -0.00141 & 0.00124 & 0.254 \\
Gender $($ girls $v$ boys) & -0.00429 & 0.00133 & 0.747 \\
Afro-Caribbean $v$ white British & 0.0100 & 0.0201 & 0.618 \\
Bangladeshi $v$ white British & -0.00187 & 0.0149 & 0.900 \\
\hline
\end{tabular}

Table 3 Multiple regression of $\log _{10} R_{\text {int }}$ on age and height

\begin{tabular}{lllc}
\hline & Coefficients & Standard error & p value \\
\hline Age $(\mathrm{y})$ & -0.0320 & 0.00790 & $<0.0001$ \\
Height $(\mathrm{cm})$ & -0.00127 & 0.00120 & 0.291 \\
\hline
\end{tabular}

interval 0.95 to 1.03), suggesting there is no important systematic bias. Measurements were made in expiration. We have shown that these are similar to those in inspiration. ${ }^{17}$

Measurements were made as described previously. ${ }^{6}$ Subjects were seated in a similar, comfortable position. They breathed quietly through a cardboard mouthpiece $(2.7 \mathrm{~cm}$ diameter or, for some of the younger children, $2.0 \mathrm{~cm}$ diameter) with the nose clipped, the cheeks and pharynx supported by the technician, and the neck slightly extended. After a period of quiet breathing, in response to a trigger during expiration at peak tidal flow, a single shutter closed automatically within $10 \mathrm{~ms}$ for $100 \mathrm{~ms}$ duration (manufacturer's speci- fication). Values were considered acceptable when the Pmo(t) was of consistent shape. ${ }^{3}$ At least six acceptable values of $\mathrm{R}_{\mathrm{int}}$ were obtained and the mean of these values was considered the measurement. Subjects were unable to anticipate the trigger but could hear the shutter closing. Attempts were not accepted if breathing was irregular or the child was restless. All new operators were trained in the method so that interrater reliability was acceptable before measurements were made in subjects. ${ }^{6}$

Height was measured in stockinged feet using calibrated wall fixed stadiometers (Castlemead, Welwyn Garden City, Hertfordshire, UK) and portable, temporarily fixed stadiometers (Raven Equipment Ltd, Dunmow, Essex, UK).

Consent was obtained with an interpreter when necessary. The study was approved by the local ethics committee.

\section{Data analysis}

Using the UK cross sectional reference data, ${ }^{18}$ heights of subjects were expressed as z scores for age and compared by one way analysis of variance.

Measurements of $\mathrm{R}_{\mathrm{int}}$ were transformed $\left(\log _{10}\right)$ to produce a constant variance. ${ }^{19}$ The relations of $\log _{10} \mathrm{R}_{\text {int }}$ and height, age, gender, and the three ethnicities were described by simple and multiple linear regression. The widths of the confidence intervals describe the adequacy of the numbers of subjects studied to identify differences between genders and ethnicities.

\section{RESULTS}

There were 130 boys (median age 6.0 years, range $2.7-10$ years) and 106 girls (median age 5.7 years, range 2.7-9.9 years). There were 39 Afro-Caribbean children (median age 5.4 years), 118 Bangladeshis (median age 6.1 years), and 79 white British (median age 5.0 years). Figure 1 shows the age distributions for subjects of each ethnicity. Seventy seven children had measurements made in schools, the remainder on hospital premises. Forty five measurements were made using the Microlab 4000 and 191 using the MicroRint.

\section{Relation of height and ethnicity}

Table 1 shows the mean $\mathrm{z}$ scores for height in the three ethnic groups. The differences are statistically significant $\left(\mathrm{F}_{232}^{2}=\right.$ 5.03, $\mathrm{p}=0.007)$.

Relation of $\mathbf{R}_{\text {int }}$ with age, height, gender, and ethnicity Table 2 shows the results of multiple regression of $\log _{10} R_{\text {int }}$ on height, age, gender, and ethnicity. It will be seen that the effects of gender and ethnicity were small and non-significant when age and height have been allowed for. Table 3 shows the results of regression on height and age. It appears that once age has been allowed for there is not a significant relation with height, but the reverse is not the case.

Table 4 gives the simple regression equations relating $\log _{10} R_{\text {int }}$ to age and height. Measurements are plotted against age and height in figs 2 and 3. Graphical examination of the residuals showed that those for age were close to normality and had a constant variability across the range. There was no evidence of curvature. The regression on height showed significant curvature.

The mean ratio of $\mathrm{R}_{\text {int }}$ measurements girls to boys corrected for age, height, and ethnicity is 0.99 (95\% CI 0.93 to 1.05). The mean ratio of $\mathrm{R}_{\text {int }}$ measurements in Bangladeshis, corrected for age, height, and gender, to those in white British is 1.00 (95\% CI 0.93 to 1.07) and those in Afro-Caribbeans compared to white British is 1.02 (95\% CI 0.93 to 1.12 ).

\section{Comparison with published data}

Published normative data measured with commercial devices are plotted in figs 4 and $5 .^{9-13}$ The data from the Korean children were from measurements made using the Microlab 4000 using the same algorithm for calculating $R_{\text {int }}$ as in this 
Table 4 Simple regressions of $\log _{10} R_{\text {int }}$ on age and height

\begin{tabular}{llllll}
\hline & Intercept & Coefficients & Standard error & $\mathrm{p}$ value & Residual standard deviation \\
\hline Age $(\mathrm{y})$ & 0.116 & -0.0396 & 0.00329 & $<0.001$ & 0.101 \\
Height $(\mathrm{cm})$ & 0.528 & -0.00569 & 0.000516 & $<0.001$ & 0.104 \\
\hline
\end{tabular}

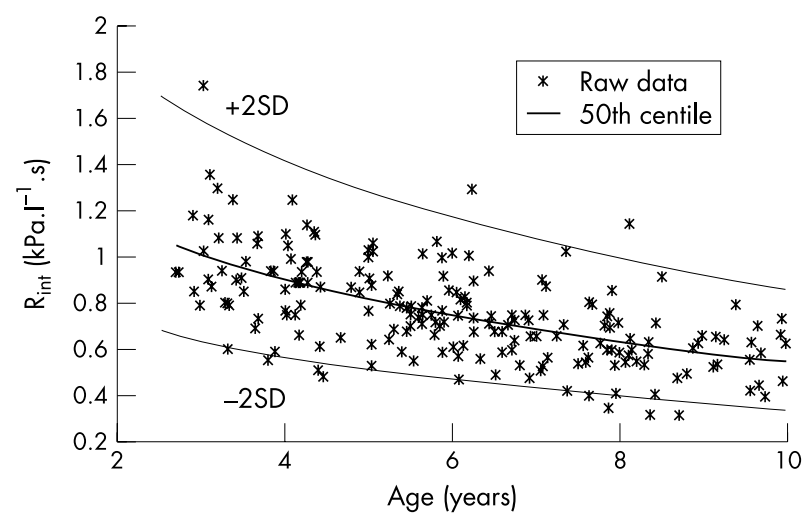

Figure 2 Measurements of $R_{\text {int }}$ related to age.

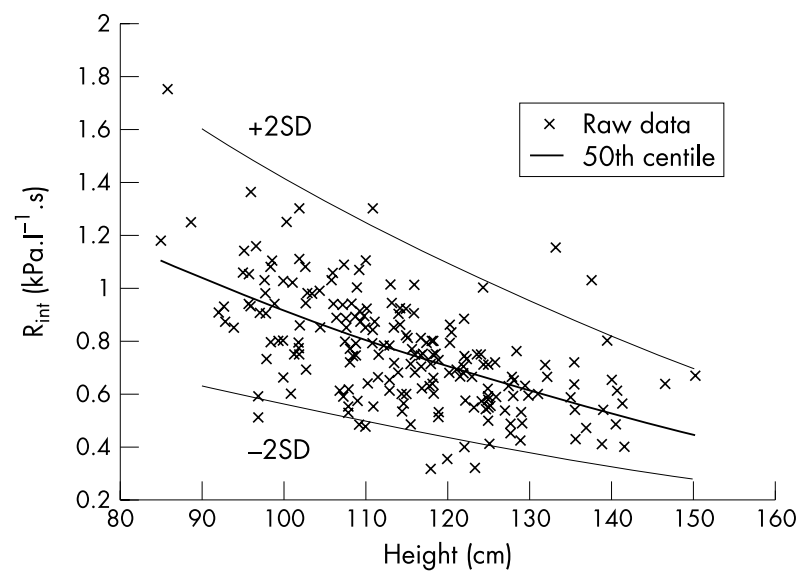

Figure 3 Measurements of $\mathrm{R}_{\text {int }}$ related to height.

study. These provide the "predicted normal values" supplied with the Micro Medical interrupter equipment. Data for airway resistance measured by plethysmography are included for comparison. ${ }^{20}$

\section{DISCUSSION}

This is the first study which measures $\mathrm{R}_{\text {int }}$ in healthy children over the age range 2 to 10 years and examines the effect of ethnicity in addition to age, height and gender. We chose a population of predominantly prepubertal children as puberty may have an independent effect on $\mathrm{R}_{\mathrm{int}}$ and would be too difficult to assess in children in a study such as this.

Our controls met standard criteria for children who are controls for respiratory disease. ${ }^{14}$ We did not ask about tobacco smoke exposure or smoking during pregnancy as it would have been impractical to validate this. Nor did we ask about family history of atopy or respiratory disease.

\section{Height, age, gender, and ethnicity}

We have presented simple regression equations, using both height and age, for comparison with other studies. We chose an exponential model because the scatter was homoscedastic after logarithmic transformation. Conventional lung function measurements such as $\mathrm{FEV}_{1}$ and FVC are usually standardised

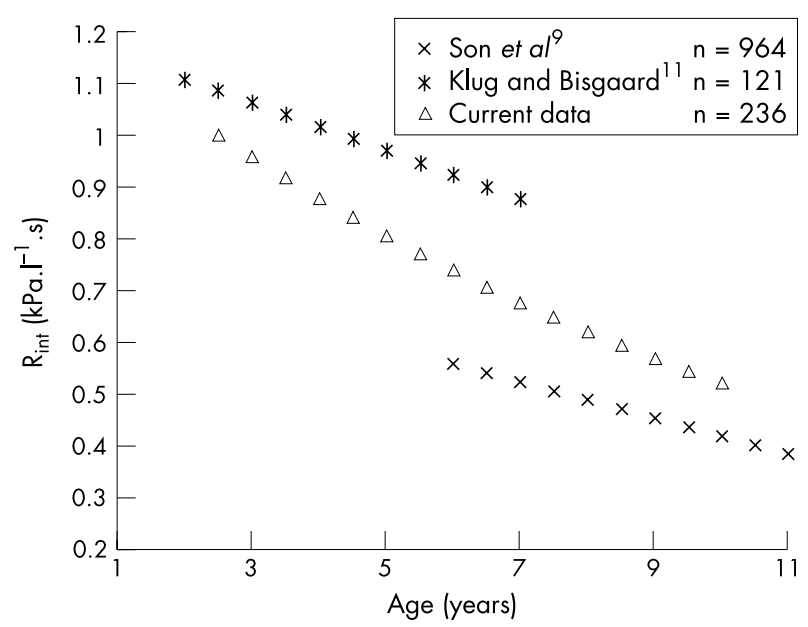

Figure 4 Published regression lines for age.

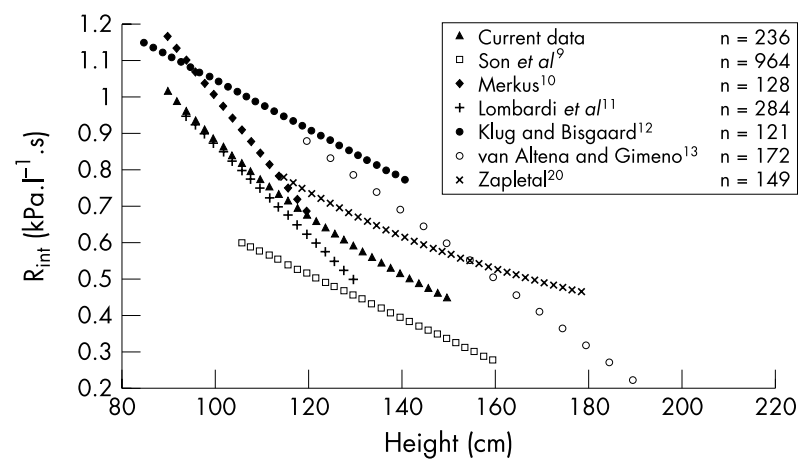

Figure 5 Published regression lines for height.

against height. In our data, height and age predicted $\mathrm{R}_{\text {int }}$ to the same extent. However, there was a small effect of age after height had been allowed for but the reverse was not the case. In addition, the age relation was linear whereas the height regression showed significant curvature even after the log transformation of $\mathrm{R}_{\text {in. }}$. Of the two, age will usually be the easier to ascertain, especially in field studies where accurate height measurement may be difficult. This is also true for measurements in physically disabled children. For practical purposes, we therefore recommend standardising $\mathrm{R}_{\mathrm{int}}$ measurements against age, at least in prepubertal children.

No significant difference in $\mathrm{R}_{\text {int }}$ between boys and girls has been identified in other studies. ${ }^{912}{ }^{13}$ In our study the $95 \%$ CI for the ratio of girls' to boys' measurements was 0.93 to 1.05 , suggesting any difference is, at the very most, $6 \%$. In infants born at term, respiratory resistance tended to be lower in girls than boys, ${ }^{21}$ but there is no information about measurements in the second year of life.

The effect of ethnicity was evaluated for the three main ethnic groups in east London. The Bangladeshi children studied here are all of Bangladeshi parents and are perceived to be a discrete ethnic group. The ethnicities of the black and white groups are likely to be less homogeneous. Nevertheless, using this classification the groups could be distinguished by height. 
We did not exclude children if their mothers smoked during pregnancy. European guidelines do not consider maternal smoking when reference values for lung function tests in children are compiled. ${ }^{22}$ About $40 \%$ of white British mothers in the area studied are believed to smoke during pregnancy ${ }^{23}$; fewer African and Afro-Caribbean mothers smoke, and the Bangladeshis rarely smoke. Smoking in pregnancy is well known to adversely affect lung function in infancy, probably reflecting smaller airways. ${ }^{23} \mathrm{R}_{\mathrm{int}}$, however, was not significantly affected by these ethnicities.

\section{Other studies}

Reference values from different workers can reflect different techniques and different populations. ${ }^{22}$ The reference data used by Micro Medical in their equipment are from a large group of Korean children. ${ }^{9}$ Measurements were technically similar to ours, although only three values rather than six were used to calculate the measurement. $\mathrm{R}_{\text {int }}$ appears to be significantly lower in the Korean children. This could be the result of a genetic influence or simply reflect a healthier population.

The Danish equations ${ }^{12}$ have been derived using the "opening" interrupter algorithm..$^{24}$ Using the Jaeger equipment, valve closure was at $50 \mathrm{ml}$ of inspired volume, ${ }^{2}$ and pressure was measured over the last $5 \mathrm{~ms}$ of an $80 \mathrm{~ms}$ occlusion. Flow was measured over $5 \mathrm{~ms}, 70 \mathrm{~ms}$ after the valve opened. Examination of the Pmo(t) transient suggests that the pressure immediately before the valve opens will be higher than that calculated by two point back extrapolation. ${ }^{3}$ If flow is similar before and after occlusion, this would explain the higher measurements in the Danish study. In addition the Danish measurements were made with subjects breathing through a mask with an integral mouthpiece. Recent work has suggested that measurements made in this way are higher than those made with only the mouthpiece. ${ }^{25}$ Van Altena and Gimeno, ${ }^{13}$ using the Jaeger device in older children and adults, measured the pressure at the end of a $100 \mathrm{~ms}$ occlusion with valve closure at a flow of $0.6 \mathrm{l} / \mathrm{s}$. Although their data for children suggest higher values than the other data sets, only 16 values for children under 11 years were included. The French measurements ${ }^{5}$ were made using a laboratory device. The valve closed at mid-tidal volume and pressure was measured by a two point, back extrapolation method at different points in the Pmo(t) transient from those used here. Flow was measured before occlusion. In this study, we have used commercially available devices. Most clinicians are likely to do the same.

\section{Summary}

We have measured $R_{\text {int }}$ in a group of healthy British children aged 2-10 years and shown that measurements were not affected by gender or by the ethnicities within the group. As has been previously recommended, ${ }^{22}{ }^{26}$ reference values from a particular population can be used for other populations if a representative sample from that population compares well. The absence of important ethnic differences in this study suggests that these data could be used for similar populations, using the same technique. Standardisation of the technique will further refine it so that interlaboratory comparisons of measurements can be made. ${ }^{27}$ The value of these data for clinical use will depend on how well $\mathrm{R}_{\text {int }}$ distinguishes healthy from sick children and the repeatability of the method. Measurements of bronchial hyperresponsiveness and bronchodilator responsiveness using the technique in preschool children have suggested that it may have a place. ${ }^{28} 29$ The repeatability of the measurement over time has been described in only a few subjects. ${ }^{10}{ }^{11}$ Until more is known about this, no claims can be made of the value of $R_{\text {int }}$ for following patients with chronic illness.

\section{Authors' affiliations}

S A McKenzie, E Chan, I Dundas, P D Bridge, C S Pao,

M Mylonopoulou, M J R Healy, Royal London Hospital, UK

\section{REFERENCES}

1 Carter ER, Stecenko AA, Pollock BH, et al. Evaluation of the interrupter technique for the use of assessing airway obstruction in children. Pediatr Pulmonol 1994;17:211-17.

2 Bisgaard $\mathbf{H}$, Klug $B$. Lung function measurement in awake young children. Eur Respir J 1995;8:2067-75.

3 Phagoo SB, Wilson NM, Silverman M. Evaluation of a new interrupter device for measuring bronchial responsiveness and the response to bronchodilator in 3 year old children. Eur Respir J 1996;9:1374-80.

4 Bridge PD, Lee H, Silverman M. A portable device based on the interrupter technique to measure bronchodilator response in schoolchildren. Eur Respir J 1996:9:1368-73.

5 Oswald-Mammosser M, Llerena C, Speich JP, et al. Measurements of respiratory system resistance by the interrupter technique in healthy and asthmatic children. Pediatr Pulmonol 1997;24:78-85.

6 Bridge PD, Ranganathan S, McKenzie SA. The measurement of airway resistance using the interrupter technique $\left(R_{\text {int }}\right)$ in pre-school children in the ambulatory setting. Eur Respir J 1999;13:792-6.

7 Bridge PD, McKenzie SA. Bronchodilator responsiveness testing in young children. Arch Dis Child 2001;84:525.

8 McKenzie SA, Bridge PD, Pao CS. Lung function tests for pre-school children. Paediatr Respir Rev 2001;2:37-45.

9 Son BK, Lim DH, Kim JH. Normal predicted values of airway resistance by flow interrupter technique in Korean primary school-aged children. Korean Paediatr Allergy Respir Dis 1998:8:198-204.

10 Merkus PJ, Mijnsbergen JY, Hop WC, et al. Interrupter resistance in preschool children. Measurement characteristics and reference values. Am J Respir Crit Care Med 2001;163:1350-5.

11 Lombardi E, Sly PD, Concutelli G, et al. Reference values of interrupter respiratory resistance in healthy preschool white children. Thorax 2001;56:691-5

12 Klug B, Bisgaard H. Specific airway resistance, interrupter resistance, and respiratory impedance in healthy children aged $2-7$ years. Pediatr Pulmonol 1998;25:322-31.

13 van Altena R, Gimeno F. Respiratory resistance measured by flow-interruption in a normal population. Respiration 1994;61:249-54.

14 Taussig LM, Chernick V, Wood R, et al. Standardization of lung function testing in children. Proceedings and Recommendations of the GAP Conference Committee, Cystic Fibrosis Foundation. J Pediatr 1980;97:668-76.

15 Chowienczyk PJ, Lawson CP, Lane S, et al. A flow interruption device for measurement of airway resistance. Eur Respir J 1991:4:623-8.

16 Lombardi E, Novembre E, Bridge PD, et al. Comparison of two devices for assessment of interrupter resistance in children [abstract]. Eur Respir J 1999; 14(suppl 30):375

17 Bridge PD, McKenzie SA. Airway resistance measured by the interrupter technique: expiration or inspiration, mean or median? Eur Respir $J$ 2001;17:495-8.

18 Chinn S, Cole TJ, Preece MA, et al. Cross-sectional stature and weight reference curves for the UK. Arch Dis Child 1995;73:17-24.

19 Healy MJR. The disciplining of medical data. Br Med Bull 1968;24:210-14.

20 Zapletal A, Samanek M, Paul T. Upstream and total airway conductance in children and adolescents. Bull Eur Physiopathol Respir 1982;18:31-7.

21 Stocks J, Henschen M, Hoo AF, et al. Influence of ethnicity and gender on airway function in preterm infants. Am J Respir Crit Care Med 1997; 156:1855-62.

22 Quanjer PH, Stocks J, Polgar G, et al. Compilation of reference values for lung function measurements in children. Eur Respir J Suppl 1989:4:184S-261S.

23 Dezateux C, Stocks J, Dundas I, et al. Impaired airway function and wheezing in infancy: the influence of maternal smoking and a genetic predisposition to asthma. Am J Respir Crit Care Med 1999;159:403-10.

24 van der Plas K, Vooren P. The "opening" interruptor. A new variant of a technique for measuring respiratory resistance. Eur J Respir Dis 1982;63:449-58

25 Child F, Clayton S, Davies S, et al. How should airways resistance be measured in young children: mask or mouthpiece? Eur Respir J 2001;17:1244-9.

26 American Thoracic Society. Lung function testing: selection of reference values and interpretative strategies. Am Rev Respir Dis 1991;144:1218.

27 Carter ER. It is time to consider standardizing the interrupter technique Eur Respir J 1997;10:1428-9.

28 Nielsen KG, Bisgaard $H$. Lung function response to cold air challenge in asthmatic and healthy children of 2-5 years of age. Am J Respir Crit Care Med 2000;161:1805-9.

29 McKenzie SA, Bridge PD, Healy MIR. Airways resistance in pre-schoo children with wheeze and cough. Eur Respir J 1999;15:833-8. 